\title{
Generation and characterization of a new mammalian cell line continuously expressing virus-like particles of Japanese encephalitis virus for a subunit vaccine candidate
}

\author{
Rong-Hong Hua*, Ye-Nan Li, Zhen-Shi Chen, Li-Ke Liu, Hong Huo, Xiao-Lei Wang, Li-Ping Guo, Nan Shen, \\ Jing-Fei Wang and Zhi-Gao Bu*
}

\begin{abstract}
Background: Japanese encephalitis virus (JEV) is the most important cause of epidemic encephalitis in most Asian regions. There is no specific treatment available for Japanese encephalitis, and vaccination is the only effective way to prevent JEV infection in humans and domestic animals. The purpose of this study is to establish a new mammalian cell line stably and efficiently expressing virus-like particle of JEV for potential use of JEV subunit vaccine.

Results: We generated a new cell clone (BJ-ME cells) that stably produces a secreted form of Japanese encephalitis virus (JEV) virus-like particle (VLP). The BJ-ME cells were engineered by transfecting BHK-21 cells with a code-optimized CDNA encoding JEV prM and E protein expression plasmid. Cell line BJ-ME can stably produces a secreted form of Japanese encephalitis virus virus-like particle (JEV-VLP) which contains the JEV envelope glycoprotein (E) and membrane protein (M). The amount of JEV-VLP antigen released into the culture fluid of BJ-ME cells was as high as 15-20 $\mathrm{mg} / \mathrm{ml}$. JEV-VLP production was stable after multiple cell passages and 100\% cell expression was maintained without detectable cell fusion or apoptosis. Cell culture fluid containing the JEV-VLP antigen could be harvested five to seven times continuously at intervals of 4-6 days while maintaining the culture. Mice immunized with the JEV-VLP antigen with or without adjuvant developed high titers of neutralizing antibodies and 100\% protection against lethal JEV challenge.

Conclusion: These results suggest that the recombinant JEV-VLP antigen produced by the BJ-ME cell line is an effective, safe and affordable subunit Japanese encephalitis vaccine candidate, especially for domestic animals such as pig and horse.
\end{abstract}

Keywords: Japanese encephalitis virus, Mammalian cell line, Virus-like particle, Subunit vaccine

\section{Background}

Japanese encephalitis virus (JEV) is the most important cause of epidemic encephalitis in most Asian regions, with about 35,000-50,000 cases of and 10,000 deaths from JEV infection reported annually [1]. The virus can be found in regions beyond its ecological boundaries, with recent reports of JEV having spread as far as northern Australia

\footnotetext{
* Correspondence: huaronghong@163.com; zgb@hvri.ac.cn

State Key Laboratory of Veterinary Biotechnology, Harbin Veterinary Research Institute, Chinese Academy of Agricultural Sciences, Maduan Street, Harbin 150001, PR China
}

[2-4] and Pakistan [5]. Hence, there is concern that JEV might become a global threat.

Japanese encephalitis (JE) caused by JEV is a mosquitoborne zoonotic infectious disease [6,7]. A variety of animals are susceptible to JEV infection, but usually only humans, horses and pigs with infection exhibit symptoms [8-11]. Humans and horses are generally thought to be dead-end JEV hosts [12,13]. Pigs are considered the most important amplification and reservoir hosts of JEV in endemic regions $[7,13]$. JEV infection in pregnant sows can cause abortion, stillbirth and other reproductive failure. In

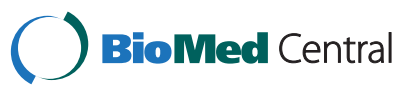

(c) 2014 Hua et al.; licensee BioMed Central Ltd. This is an Open Access article distributed under the terms of the Creative Commons Attribution License (http://creativecommons.org/licenses/by/4.0), which permits unrestricted use, distribution, and reproduction in any medium, provided the original work is properly credited. The Creative Commons Public Domain Dedication waiver (http://creativecommons.org/publicdomain/zero/1.0/) applies to the data made available in this article, unless otherwise stated. 
addition, infection of boars can cause acute testicular inflammation and hypospermia [14,15].

There is no specific treatment available for JE, and vaccination is the only effective way to prevent JEV infection in humans and domestic animals. At present, there are three kinds of JE vaccines available for humans: the live attenuated virus vaccine SA14-14-2 [16-19], Vero cellderived formalin-inactivated whole-virus SA14-14-2 strain vaccine IC51 and Beijing-1 strain vaccine JEBIKV [19-21], and recombinant chimeric virus vaccine JE-CV [22,23]. These vaccines have better safety profiles and fewer side effects compared with the mouse brain-derived inactivated vaccine [24-26]. The attenuated live vaccine is derived from primary hamster kidney cells, is difficult and costly to manufacture, and the infectious agents are always associated with potential biosafety issues.

The use of infectious agents is always a major issue with manufacturing process of the currently used vaccines. Therefore, the development of new types of JE vaccines for humans and domestic animals that do not involve the use of infectious JEV is imperative. Genetically engineered vaccine is a potential new form of the JE vaccine. Previous studies have shown that the pre-membrane (prM) and E protein expressed in mammalian cells could assemble into virus-like particles (VLP), and that the expressed JEV VLP has the same ability to induce neutralizing antibodies and protective efficiency as the JEV virion [27-30]. Thus, studies on second-generation JE vaccines have focused on the production of the JEV-VLP antigen by genetic engineering of a stable cell line. Different mammalian cell lines including RK13 [31], COS-1 [32] and CHO-k1 [33] have been used to construct stable cell lines that continuously express JEV-VLP, but do not express efficiently or have additional defects.

In this study, we have generated a new cell line, BJ-ME, which can stably produce a secreted form of the JEV VLP by using BHK-21 cells as the parent cell line. Mice immunized with the expressed JEV-VLP antigen developed high titres of neutralizing antibodies and complete protection against lethal JEV challenges.

\section{Results}

\section{Establishment of a stable cell clone continuously expressing the prM/M-E antigen}

From the cloned colonies of BHK-21 cells, 64 G418-resistant and E protein-specific IFA-positive cell colonies were picked and transferred to 24-well plates. After comparison of $\mathrm{E}$ protein expression in the culture medium of the 64 cell colonies by Western blotting, 10 clones with relatively high E protein expression were selected for further comparison. After IFA testing and further cloning purification, the $\mathrm{E}$ protein expression efficiency of all 10 cell clones was compared using E protein-specific Western blotting. The clone of most efficiently expression $\mathrm{E}$ antigen was selected and designated as BJ-ME (BHK-JEV-ME). The cells were expanded and maintained in G418-containing medium to observe JEV antigen production. The BJ-ME cell clone had undistinguishable morphology from parental BHK-21 cells and induced no polykaryocyte formation. When the fifth-passage BJ-ME cells were examined by indirect immunofluorescence and flow cytometry, over $94 \%$ of BJ-ME cells were positively stained with JEV E proteinspecific MAb 5E7. This high percentage of E-expressing cells was maintained till the twentieth passage (Figure 1).

Western blotting results with the MAbs 5E7 and 3C8 showed that BJ-ME cells expressed the prM and E protein together, and the majority of prM in the cells did not show cleavage. When secreted into culture medium, most of the prM protein was cleaved by furin into mature $M$ protein (Figure 2).

The morphology of BJ-ME cells was further examined by transmission electron microscopy. The results showed that VLP structure was observed in the endoplasmic reticulum of cells (Figure 3A,B), and this JEV-VLP structure was further confirmed with purified JEV-VLP by negative staining electron microscopy observation (Figure 3C). The appearance of the JEV-VLP was in the form of particles with an average diameter of $40-50 \mathrm{~nm}$ surrounded by a lipid bilayer.

\section{Passage stability and antigen expression of BJ-ME cells}

For BJ-ME cells, passage 1 was defined as the cell culture from the 96-well plate by limiting dilution cloning and with $100 \%$ E expression. After expansion and cryopreservation, the culture medium of BJ-ME cells cultured in $75 \mathrm{~cm}^{2}$ flasks was collected from passage 5 . The JEV-VLP was purified by ultrafiltration and rate zonal centrifugation. The purified antigen was used in negative staining electron microscopy observation and used as the antigen standard in an antigen capture ELISA quantification assay.

To evaluate the antigen expression dynamics of BJ-ME cells, the confluent BJ-ME cells were passaged 1:5 into $75 \mathrm{~cm}^{2}$ flasks with $20 \mathrm{ml}$ medium containing 10\% FBS. For antigen amounts detection, in next day, the cells started growing in confluence and the medium containing 10\% FBS were changed into maintaining medium (containing 1\% FBS). Twenty four hours later, $600 \mu \mathrm{l}$ of the culture medium was replaced with fresh serum-free medium every day. The amount of JEV-VLP was determined by ELISA. As shown in Figure 4A, the amount of JEV-VLP in the culture medium kept increasing in the first four days. From the fifth day, it reached a plateau, after which it started showing a slight increase from the fifth to tenth day. Cell culture fluid containing the JEVVLP antigen could be harvested five to seven times continuously at intervals of 4 to 6 days during culture, and the concentration of JEV-VLP antigen collected at each harvest was over $15 \mu \mathrm{g} / \mathrm{ml}$ (Figure 4B). 


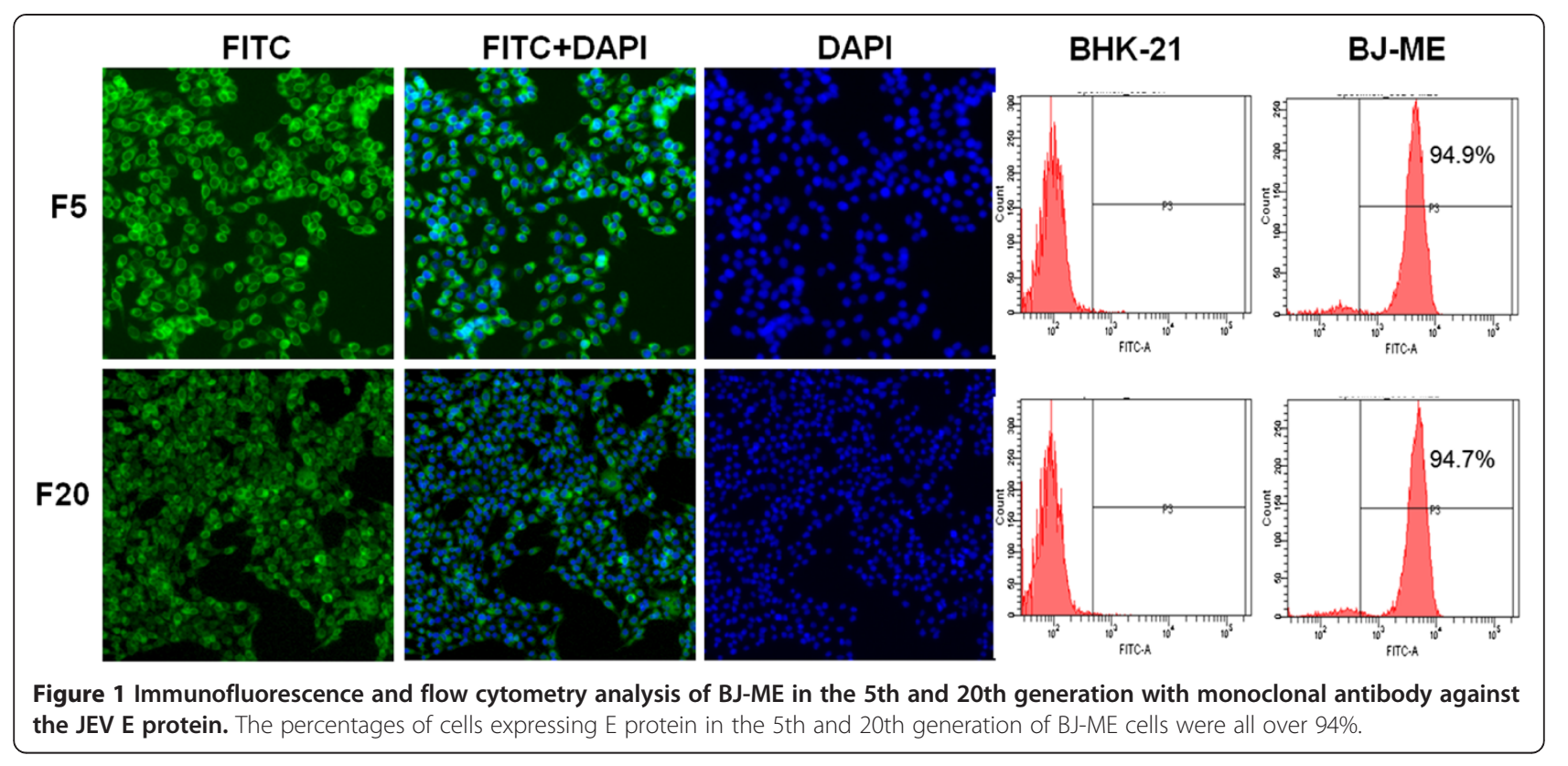

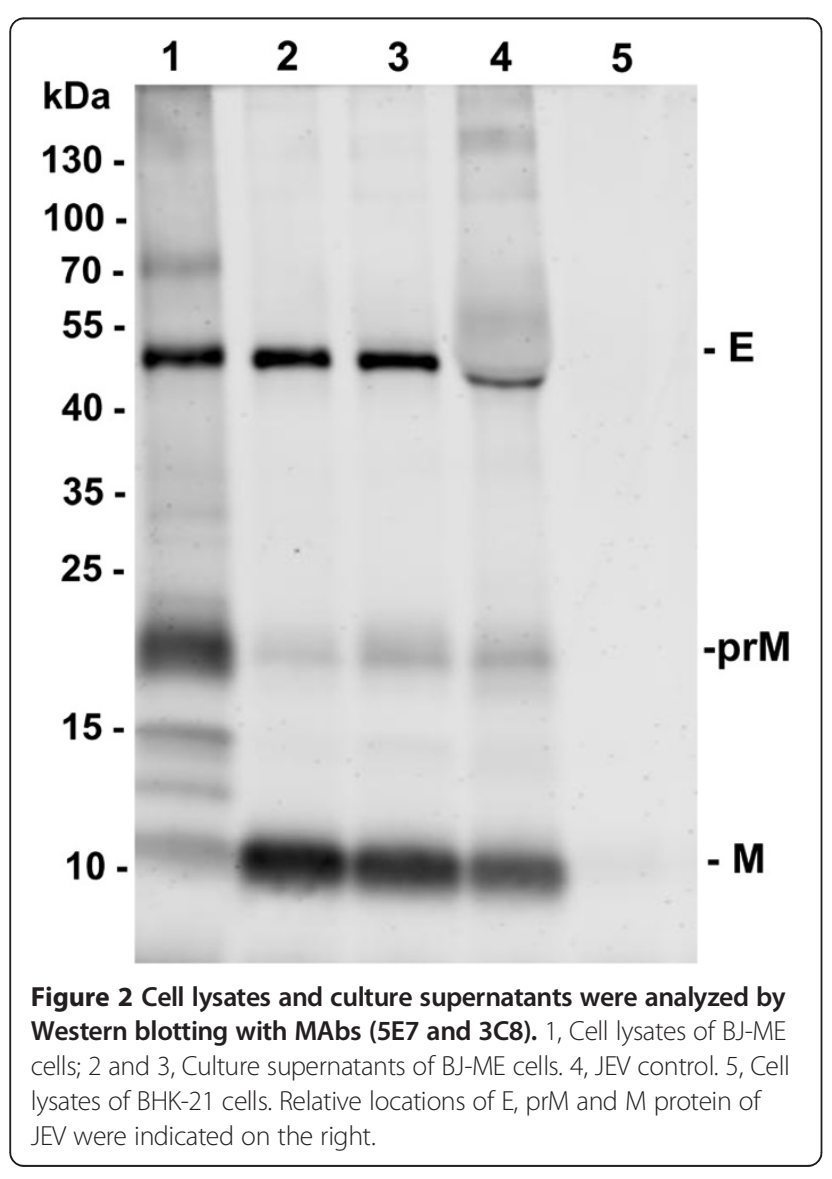

The stability of JEV-VLP antigen expression by BJ-ME cells was further evaluated using cryopreserved cells. After thawing, BJ-ME cells were passaged every 2 days in $75 \mathrm{~cm}^{2}$ flasks. For antigen testing, the culture medium of confluent cells were changed into fresh maintaining medium. 4 to 5 days later the culture medium was collected at the $5^{\text {th }}, 10^{\text {th }}, 15^{\text {th }}$, and $20^{\text {th }}$ passages and examined for the amount of JEV-VLP antigen by ELISA (Figure 4C). Although the amount of JEV-VLP antigen produced by BJ-ME cells differed little between passages, more than $15 \mu \mathrm{g} / \mathrm{ml}$ of the JEV-VLP antigen was detectable throughout the monitoring period. Even at the $20^{\text {th }}$ passage, the frequency of E-expressing cells was over 94\% (Figure 1).

\section{Immunogenicity and protective efficacy of the JEV-VLP}

Mice administered the JEV-VLP with or without adjuvant developed high titers of neutralizing antibody. Even the neutralizing antibody titer in mice that were not administered the adjuvant was somewhat higher than that observed in mice immunized with the live virus vaccine (Table 1). All mice immunized with the JEV-VLP with or without adjuvant and the live virus vaccine were completely protected against JEV. All mice that were administered PBS died within 10 days after the challenge (Figure 5A).

For the second experiment, the immunogenicity and protective efficacy of different doses of the antigen were evaluated. As shown in Table 1, mice in the groups administered $3 \mu \mathrm{g}$ and $2 \mu \mathrm{g}$ of the antigen developed high levels of neutralizing antibody similar to that of the live vaccine group and were completely protected against the JEV challenge. Mice in the groups administered 0.3-1.5 $\mu \mathrm{g}$ of the antigen developed relatively lower titers of neutralizing 


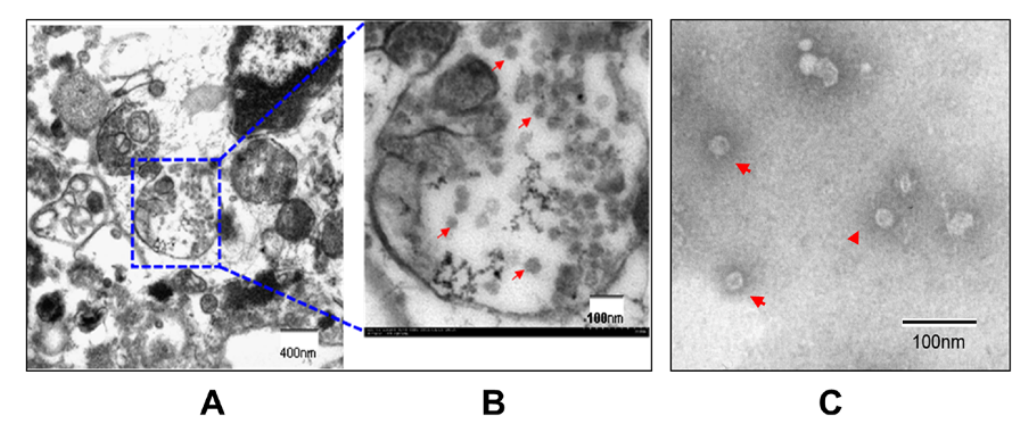

Figure 3 Electron micrographs of BJ-ME expression of JEV VLP. (A) Low-magnification image of BJ-ME cells. (B) Higher magnification image of BJ-ME cells. Virus-like particles in the ER of BJ-ME cells are indicated with arrowheads. (C) JEV VLP purified from the culture supernatant of BJ-ME cells. The purified antigen was processed for negative staining and observed with an electron microscope.

antibody, and were partially protected against JEV; however, the survival rate in all groups was higher than $70 \%$ (Table 1, Figure 5B).

\section{Discussion}

There is an urgent need for an effective, affordable and safer JE vaccine for humans and domestic animals. Biotechnicallyengineered cell lines expressing the JEV-VLP antigen may meet this requirement. Here, we describe another alternative, a recombinant subunit vaccine candidate, based on a new mammalian cell line.

The BJ-ME cells described in this study produce extremely high levels of the JEV-VLP antigen-15-20 $\mu \mathrm{g}$ / $\mathrm{ml}$-which is higher than that of any other reported cell lines such as J12\#26 [31], F [33] and JE-4B [32]. This value was determined under experimental conditions involving simple changes in the culture medium, and we believe that the titer could be further increased under optimal culture conditions. Moreover, time-course results suggest that 5 days of incubation is sufficient for antigen production.

BJ-ME cells had similar cell morphology and growth characteristics as the parental BHK-21 cells. In fact, cell clones with different morphogenetic characteristics found during the selection and cloning process were found to release the $\mathrm{E}$ antigen inefficiently. This phenomenon indicates that maintaining similar morphology and growth characteristics with the parental cells may be important in the engineering of cell lines with high efficiency and stable exogenous gene expression. Another factor that may have contributed to the high efficiency of JEV-VLP antigen expression in $\mathrm{BJ}-\mathrm{ME}$ cells is the genetic codon optimization of the cDNA sequence encoding the prM and E proteins. Different species have codon usage bias, and optimizing the genetic codon according to the bias of the expressing host could increase the expression efficiency of the target gene [34-36]. The BJ-ME cells showed stable JEV-VLP production during cell culture and passage. Even after 20-
25 passages, the JEV-VLP antigen-producing efficiency of BJ-ME cells was not significantly reduced.

A major obstacle to the stable expression of flavivirus membrane protein in mammalian cells is its cytotoxicity. In a previous report, attempts to establish cells with high expression of the prM-E protein from Vero cells were unsuccessful [31]. This is probably because Vero cells are susceptible to JEV infection, which makes them sensitive to the cytotoxic effects of the JEV-VLP antigen. Although BHK-21 cells are susceptible to JEV infection, we did not observe any obvious cytotoxic effects of JEV VLP. It was possible to obtain dozens of G418-resistant cell colonies with a single transfection and selection cycle. The cell line BJ-ME constructed in this study has the same growth characteristics as the parent cell line BHK-21. So this cell line could easily be cultured in serum-free or low-serum medium. J12\#26 cells derived from RK13, a rabbit kidney cell line, was the most stable and highest antigen-producing cell line in all previous reports [31]. However, RK13 cells grow slowly and could not reach high cell density, so are not suitable for largescale culture. Another important point is that RK13 cells contain bovine viral diarrhea virus [37], which make them unsuitable for vaccine antigen production.

To overcome the fusogenic cytotoxicity of JEV prM-E protein expression in mammalian cell lines, Konishi et al. [33] introduced a mutation at the $\mathrm{prM} / \mathrm{M}$ cleavage site to prevent authentic processing and to reduce the toxic fusion activity of the expressed VLP, and established an F-cell line using CHO-k1 as the parent cell line. The elimination of cleavage of the prM protein resulted in the production of immature VLPs, which are quite different in their conformational structure from the mature VLPs produced by authentic cleavage of prM [38]. These structural differences may eliminate virus conformational neutralizing epitopes. Moreover, reports have shown that most JEV-neutralizing epitopes are conformation dependent [39]. The differences in the conformational structure will 


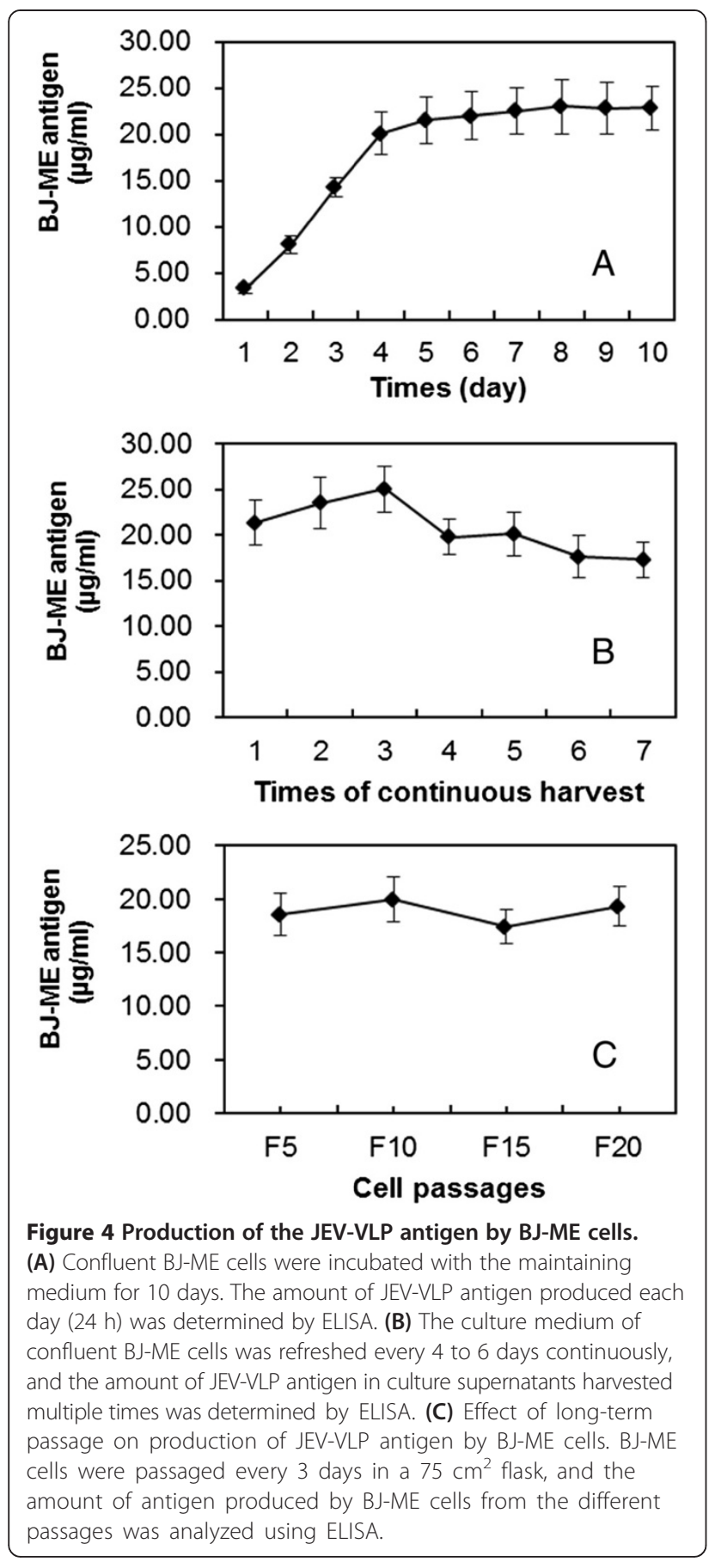

affect the immunogenicity of the F antigen. In fact, the protection rate in mice immunized with the $\mathrm{F}$ antigen with uncleaved prM protein did not exceed 50\% [33]. Recently Yamaji et al. further reported expressing the JEV prM protein mutated virus-like particles with baculovirus [40] and lepidopteran insect cell lines [41]. Obviously the yield of $E$ antigen were increased in both of two expressing systems, especially the $\mathrm{E}$ antigen yield reached about $30 \mu \mathrm{g} / \mathrm{ml}$ in lepidopteran insect cell line. However, these studies did not present immune protection result of these immature JEV virus-like particles with uncleaved prM protein. The differences in structural and immune protective effect between immature and mature JEV virus-like particles need further evaluation. Maybe DENV-related reports $[42,43]$ could provide some clues for future survey the relation of immune protective effect and structure of virus-like particles.

As expected be of particulate form, the BJ-ME antigen was immunogenic. With or without adjuvant, dose of $2 \mu \mathrm{g}$ of BJ-ME induced high titers of neutralizing antibodies and provided complete protection against challenge. However we observed no enhancement effect of the adjuvant in this experiment which may because the antigen amount of $2 \mu \mathrm{g}$ is overdosed for mice. Another experiment with different dose of antigen showed that $0.3 \mu \mathrm{g}$ of BJ-ME antigen could induce effective protection neutralizing antibodies titer of 1:40 which is higher than surrogate maker for seroprotection of neutralizing antibody titer of 1:10.

\section{Conclusions}

The new established cell line BJ-ME could efficiently and stably produces secreted form of JEV-VLP. BJ-ME cells expressing the JEV-VLP antigen showed good immunogenicity in mice. An antigen dose of at least $0.3 \mu \mathrm{g}$ could induce neutralizing antibody production, and more than $70 \%$ of immunized mice survived after lethal challenge with JEV. These results suggest that the recombinant JEV virus-like particle antigen produced by the BJ-ME cell clone is an effective, easy to produce, and safe second-generation subunit JE veterinary vaccine candidate. Moreover, the JEV-VLP could be used to make diagnostic reagents for JE and JEV.

\section{Methods}

\section{Animal ethics}

Care of laboratory animals and animal experimentation were performed in accordance with animal ethics guidelines and approved protocols. All animal experiments were approved by the Animal Ethics Committee of Harbin Veterinary Research Institute of the Chinese Academy of Agricultural Sciences. The Animal Ethics Committee approval number was SYXK (Hei) 2011-022.

\section{Cells and viruses}

Baby hamster kidney BHK-21 cells (CCL-10; ATCC) were cultured in Dulbecco's modified Eagle's medium (DMEM; Gibco, Invitrogen, Carlsbad, CA) supplemented with 10\% fetal bovine serum (FBS; Gibco, Grand Island, NY). C6/36 cells (CRL-1660; ATCC) were cultured at $28^{\circ} \mathrm{C}$ in a $5 \%$ $\mathrm{CO}_{2}$ atmosphere in RPMI-1640 (Gibco, Grand Island, NY) supplemented with 10\% FBS. The attenuated JEV vaccine strain SA14-14-2 was propagated and titrated on 
Table 1 Induction of neutralizing antibodies in mice vaccinated with the JEV-VLP antigen

\begin{tabular}{|c|c|c|c|c|c|}
\hline \multirow[t]{2}{*}{ Expt } & \multirow[t]{2}{*}{ Vaccine } & \multirow[t]{2}{*}{ Dosage } & \multicolumn{2}{|c|}{ Neutralizing antibody titer ${ }^{a}$} & \multirow{2}{*}{$\begin{array}{l}\text { Survival rate } \\
\text { (no. alive/total }\end{array}$} \\
\hline & & & Day 14 & Day 28 & \\
\hline \multirow[t]{5}{*}{1} & BJ-ME $^{\mathrm{b}}$ (oil adjuvant) & $2 \mu \mathrm{g}$ & 40 & 100 & $100 \%(10 / 10)$ \\
\hline & BJ-ME (no adjuvant) & $2 \mu \mathrm{g}$ & 70 & 100 & $100 \%(10 / 10)$ \\
\hline & BJ-ME (no adjuvant) & $4 \mu \mathrm{g}$ & 100 & 280 & $100 \%(10 / 10)$ \\
\hline & Live $\operatorname{vac}^{\mathrm{c}}$ & $10^{6} \mathrm{TCID}_{50}$ & 100 & 120 & $100 \%(10 / 10)$ \\
\hline & PBS & $200 \mu \mathrm{L}$ & $<10$ & $<10$ & $0 \%(0 / 10)$ \\
\hline \multirow[t]{7}{*}{2} & BJ-ME $200 \mu \mathrm{l}$ & $3 \mu \mathrm{g}$ & ND & 160 & $100 \%(8 / 8)$ \\
\hline & BJ-ME $150 \mu \mathrm{l}$ & $2.25 \mu \mathrm{g}$ & ND & 140 & $100 \%(8 / 8)$ \\
\hline & BJ-ME $100 \mu \mathrm{l}$ & $1.5 \mu \mathrm{g}$ & ND & 100 & $87.5 \%(7 / 8)$ \\
\hline & BJ-ME $50 \mu \mathrm{l}$ & $0.75 \mu \mathrm{g}$ & ND & 70 & $87.5 \%(7 / 8)$ \\
\hline & BJ-ME $20 \mu \mathrm{l}$ & $0.3 \mu \mathrm{g}$ & ND & 40 & $75 \%(6 / 8)$ \\
\hline & Live vac & $10^{6} \mathrm{TCID}_{50}$ & ND & 160 & $100 \%(8 / 8)$ \\
\hline & PBS & $200 \mu \mathrm{L}$ & ND & $<10$ & $0 \%(0 / 8)$ \\
\hline
\end{tabular}

${ }^{a}$ Titers are expressed as the maximum serum dilution yielding a 50\% plaque reduction. ${ }^{b}$ JEV-VLP antigen. ${ }^{c}$ Live virus vaccine (SA14-14-2 strain). ND, not determined.

BHK-21 cell monolayers, and stored at $-80^{\circ} \mathrm{C}$ until use. The P3 strain of JEV used to challenge mice was propagated in mouse brains. The P3 strain of JEV used in the plaque reduction neutralizing assay was passaged through C6/36 cells twice, and then passaged twice through BHK21 cells.

\section{Construction of plasmids carrying the prM and E genes of JEV}

First, a genetic codon-optimized JEV cDNA encoding the viral signal peptide of the carboxyl terminus of the C, prM, and E protein of the SA14-14-2 strain (amino acid positions 106 to 794, GenBank: AAK11279.1) was synthesized and cloned into the pUC57 plasmid. Then DNA fragment was subcloned into the the expression vector pCAGneo to generate pCAGneo-opti-JEV-ME. The plasmid pCAGneo contains the neomycin resistance gene, which confers resistance to G418. The resulting plasmid pCAGneo-opti-JEV-ME was used to transfect stable cell lines.

\section{Establishment of stable cell lines constitutively producing the $\mathrm{E}$ antigen}

Monolayer or subconfluent BHK-21 cells were transfected with the pCAGneo-opti-JEV-ME plasmid using FuGENE HD transfection reagent (Roche Diagnostic $\mathrm{GmbH}$, Mannheim, Germany). Two days later, the transfected cells were digested and cloned by limited dilution in 96-well plates and growth in medium containing G418 $(1000 \mu \mathrm{g} / \mathrm{ml})$. The cloned cells were selected by Indirect immunofluorescence assay (IFA) with JEV E proteinspecific monoclonal antibody 5E7 (unpublished data). The amount of $\mathrm{E}$ antigen in culture supernatants from cloned cells was examined and compared by Western blotting. One clone designated BJ-ME (BHK-JEV-ME) that showed obviously more efficient expression of the $\mathrm{E}$ antigen was

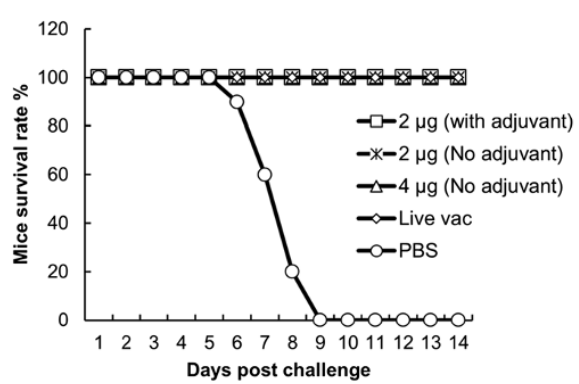

A

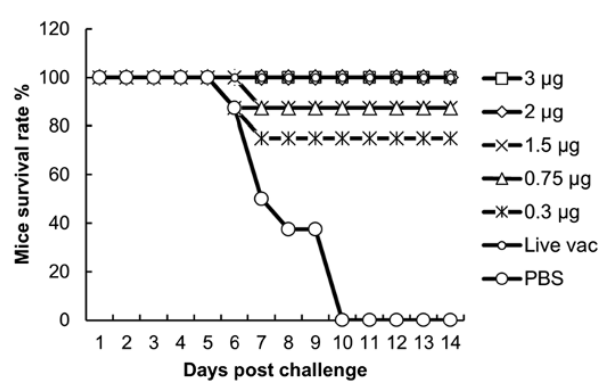

B

Figure 5 Protection of mice against challenge with JEV. (A) Groups of 10 4-week-old BALb/c mice were vaccinated as in Table 1 experiment 1. Immunized mice in all groups of JEV-VLP with or without adjuvant survived in 100\%. (B) Survival rate of different dosage of JEV-VLP immunized mice. All mice were challenged with $1.0 \times 10^{7}$ PFU of the P3 strain of JEV. 
selected and maintained for further characterization and antigen production.

\section{Indirect immunofluorescence assays and flow cytometry analysis}

The cells were washed with phosphate-buffered saline (PBS), fixed with $4 \%$ paraformaldehyde at room temperature for 20 min, washed and then premeabilized with PBS containing $0.1 \%$ Triton X-100 (PBS-T). Then the cells were probed with JEV E protein-specific MAb 5E7 or JEV prM/M protein-specific MAb 3C8 at the procedure described before [44]. And cell nuclei were stained with DAPI (4',6-Diamidino-2-phenylindole dihydrochloride). Cells were then observed under a fluorescence microscope (IMT2 Olympus, Tokyo, Japan). For flow cytometry analysis, the cells were dispersed by trypsin digestion and then fixed as above described.

\section{Antigen purification}

The culture medium collected at 4-6 days after subculture of BJ-ME cells was clarified by centrifugation. The clarified medium was concentrated 40 -fold in volume by ultrafiltration with a membrane with a size exclusion limit of $100 \mathrm{kDa}$ (Biomax100; Millipore, Bedford, MA, USA). The concentrate was subjected to rate zonal centrifugation in 10-50\% (wt/wt) linear sucrose gradients. Fractions were collected and analyzed by SDS-PAGE and Western blotting for the $\mathrm{E}$ antigen. Fractions of $20-30 \%$ sucrose were collected and pooled. Sucrose was removed from the E antigen pool by Sephadex G-25 chromatography with the NAP-25 column (GE, Westborough, MA, USA), equilibrated and eluted with PBS. The purified JEV-VLP in PBS was quantified with quick-start Bradford protein assay kits (Bio-Rad Laboratories Inc., Hercules, CA, USA) according to the manufacturer's instructions.

\section{Western blotting analysis}

JEV-VLP antigen in BJ-ME cell culture supernatants or cell lysates were analyzed by Western blot analysis at the procedure described previously [44]. The membrane was probed with MAb 5E7 or/and 3C8.

\section{Antigen capture ELISA for quantification of antigen}

The amounts of the BJ-ME antigen were quantified by a sandwich ELISA with a pair of JEV specific MAb. 5E7 and $5 \mathrm{~B} 10$ which were generated with purified BJ-ME antigen according to the procedure described previously [44-46]. Briefly MAb 5B10 (2 $\mu \mathrm{g} / \mathrm{ml})$ was coated on 96well plates overnight at $4^{\circ} \mathrm{C}$, and blocked with $5 \%$ skimmed dried milk for $2 \mathrm{~h}$ at $37^{\circ} \mathrm{C}$. Subsequently, the plates were washed three times with phosphate-buffered saline with $0.1 \%$ Tween-20 (PBST). In the binding assay, the plates were incubated with the various dilutions of samples at $37^{\circ} \mathrm{C}$ for $2 \mathrm{~h}$ followed by washing three times with PBST.
Bound antigens were detected with horseradish peroxidase (HRP)-conjugated MAb 5E7. After additional incubation $37^{\circ} \mathrm{C}$ for $1 \mathrm{~h}$ and thorough washing with PBST, the reactions were developed with TMB substrate. The reaction was stopped with $2 \mathrm{M} \mathrm{H}_{2} \mathrm{SO}_{4}$, and absorbance was measured at $450 \mathrm{~nm}$ using a microplate autoreader (Bio-Rad, Hercules, CA, USA). The results are presented as the average of duplicate assays. A stock of purified BJ-ME antigen was serially twofold diluted and used as standards. The antigen amounts of each sample were determined from the standard curve.

\section{Electron microscopic observation}

Virus-like particles in BJ-ME cells were examined with transmission electron microscope as reported procedure [31]. For observation of BJ-ME cells expressing VLP in the culture supernate, the purified JEV-VLP was processed for negative staining on copper formvar-coated grids. Specimens were stained with sodium phosphotungstate and observed under an electron microscope.

\section{Immunization and challenge of mice}

The supernates of BJ-ME cells cultured for 6 days without FBS were harvested and used for immunization. Supernates containing $20 \mu \mathrm{g} / \mathrm{ml}$ antigen emulsified with the same volume of MONTANIDE ISA50V2 (SEPPIC S.A., Paris, France) were used for immunization with a $200 \mu \mathrm{l}$ dose to each mouse. Other two groups of 4-week-old female BALB/c mice were immunized subcutaneously with a $200 \mu \mathrm{l}$ (for $4 \mu \mathrm{g}$ antigen without adjuvant group) and $100 \mu \mathrm{l}$ (for $2 \mu \mathrm{g}$ antigen without adjuvant group) dose given to each mouse. PBS and $10^{6.5} \mathrm{TCID}_{50} / 0.2 \mathrm{ml}$ of the attenuated JEV vaccine strain SA14-14-2 given at the same dose were used as the negative and positive control, respectively. Two weeks after the first immunization, an enhanced immunization was given. Except for only once immunization was given for the live virus vaccine group. Mice were bled at intervals of 2 weeks for up to 4 weeks after the first immunization. Pooled serum samples from each group were stored for virus neutralizing antibody testing. Mice were challenged with intraperitoneal injections at the day after the last bleed with a $1.0 \times 10^{7} \mathrm{PFU}$ of the P3 strain of JEV and observed for 2 weeks.

In another experiment, the supernates containing different amount of antigen ( $0.3 \mu \mathrm{g}$ to $3 \mu \mathrm{g}$ per mouse) without adjuvant were used as immunogen. Groups of eight 4week-old BALB/c mice were immunized, bled and challenged as described above. PBS and the live virus vaccine control groups were also conducted as described above.

\section{Neutralizing antibody testing}

Virus neutralizing antibodies present in the mouse and pig sera were tested using a plaque reduction assay [31]. Except that BHK-21 cells were used rather than Vero 
cells. Neutralizing antibody titers were expressed as the reciprocal of the serum dilution yielding a $50 \%$ reduction in the mean plaque number versus that in the control wells.

\section{Competing interests}

The authors declare that they have no competing interests.

\section{Authors' contributions}

$\mathrm{RHH}$ and $\mathrm{ZGB}$ designed the experiment. RHH, YNL, ZSC, LKL, HH, XLW, LPG, NS and JFW performed the experiments. RHH and ZGB analysed data and wrote the paper. All authors read and approved the final manuscript.

\section{Acknowledgements}

This work was supported by grants from the Special Fund for Agro-scientific Research in the Public Interest of China (201203082) and the Basic Scientific Research Fund of Central Research Academies and Institutes (ZGKJ201106, 1610302013011)

Received: 20 June 2014 Accepted: 4 July 2014

Published: 10 July 2014

\section{References}

1. Solomon T, Vaughn DW: Pathogenesis and clinical features of Japanese encephalitis and West Nile virus infections. Curr Top Microbiol Immunol 2002, 267:171-194.

2. Hanna JN, Ritchie SA, Phillips DA, Shield J, Bailey MC, Mackenzie JS, Poidinger M, McCall BJ, Mills PJ: An outbreak of Japanese encephalitis in the Torres Strait, Australia, 1995. Med J Aust 1996, 165:256-260.

3. van den Hurk AF, Nisbet DJ, Johansen CA, Foley PN, Ritchie SA, Mackenzie JS: Japanese encephalitis on Badu Island, Australia: the first isolation of Japanese encephalitis virus from Culex gelidus in the Australasian region and the role of mosquito host-feeding patterns in virus transmission cycles. Trans R Soc Trop Med Hyg 2001, 95:595-600

4. Mackenzie JS, Johansen CA, Ritchie SA, van den Hurk AF, Hall RA: Japanese encephalitis as an emerging virus: the emergence and spread of Japanese encephalitis virus in Australasia. Curr Top Microbiol Immunol 2002, 267:49-73.

5. Igarashi A, Tanaka M, Morita K, Takasu T, Ahmed A, Akram DS, Waqar MA: Detection of west Nile and Japanese encephalitis viral genome sequences in cerebrospinal fluid from acute encephalitis cases in Karachi, Pakistan. Microbiol Immunol 1994, 38:827-830.

6. Halstead SB, Jacobson J: Japanese encephalitis. Adv Virus Res 2003, 61:103-138.

7. van den Hurk AF, Ritchie SA, Mackenzie JS: Ecology and geographical expansion of Japanese encephalitis virus. Annu Rev Entomol 2009, 54:17-35.

8. See E, Tan HC, Wang D, Ooi EE, Lee MA: Presence of hemagglutination inhibition and neutralization antibodies to Japanese encephalitis virus in wild pigs on an offshore island in Singapore. Acta Trop 2002, 81:233-236.

9. Pant GR: A serological survey of pigs, horses, and ducks in Nepal for evidence of infection with Japanese encephalitis virus. Ann N Y Acad Sci 2006, 1081:124-129.

10. Lim SI, Kweon CH, Tark DS, Kim SH, Yang DK: Sero-survey on Aino, Akabane, Chuzan, bovine ephemeral fever and Japanese encephalitis virus of cattle and swine in Korea. J Vet Sci 2007, 8:45-49,

11. Yang DK, Kweon CH, Kim BH, Hwang IJ, Kang MI, So BJ, Cho KO: The seroprevalence of Japanese encephalitis virus in goats raised in Korea. $J$ Vet Sci 2007, 8:197-199.

12. Erlanger TE, Weiss S, Keiser J, Utzinger J, Wiedenmayer K: Past, present, and future of Japanese encephalitis. Emerg Infect Dis 2009, 15:1-7.

13. McArthur MA, Holbrook MR: Japanese Encephalitis Vaccines. J Bioterror Biodef 2011, S1:2.

14. van-den-Hurk AF, Ritchie SA, Johansen CA, Mackenzie JS, Smith GA: Domestic pigs and Japanese encephalitis virus infection, Australia. Emerg Infect Dis 2008, 14:1736-1738.

15. Lindahl J, Boqvist S, Stahl K, Thu HT, Magnusson U: Reproductive performance in sows in relation to Japanese Encephalitis Virus seropositivity in an endemic area. Trop Anim Health Prod 2012, 44:239-245.
16. Xin $Y Y$, Ming $Z G$, Peng GY, Jian A, Min LH: Safety of a live-attenuated Japanese encephalitis virus vaccine (SA14-14-2) for children. Am J Trop Med Hyg 1988, 39:214-217.

17. Liu ZL, Hennessy S, Strom BL, Tsai TF, Wan CM, Tang SC, Xiang CF, Bilker WB, Pan XP, Yao YJ, Xu ZW, Halstead SB: Short-term safety of live attenuated Japanese encephalitis vaccine (SA14-14-2): results of a randomized trial with 26,239 subjects. J Infect Dis 1997, 176:1366-1369.

18. Bista MB, Banerjee MK, Shin SH, Tandan JB, Kim MH, Sohn YM, Ohrr HC, Tang JL, Halstead SB: Efficacy of single-dose SA 14-14-2 vaccine against Japanese encephalitis: a case control study. Lancet 2001, 358:791-795.

19. Kollaritsch H, Paulke-Korinek M, Dubischar-Kastner K: IC51 Japanese encephalitis vaccine. Expert Opin Biol Ther 2009, 9:921-931.

20. Dubischar-Kastner K, Eder S, Buerger V, Gartner-Woelfl G, Kaltenboeck A, Schuller E, Tauber E, Klade C: Long-term immunity and immune response to a booster dose following vaccination with the inactivated Japanese encephalitis vaccine IXIARO, IC51. Vaccine 2010, 28:5197-5202.

21. Kikukawa A, Gomi Y, Akechi M, Onishi T, Manabe S, Namazue J, Fuke I, Ishikawa T, Okuno Y, Ueda S: Superior immunogenicity of a freeze-dried, cell culture-derived Japanese encephalitis vaccine (inactivated). Vaccine 2012, 30(13):2329-2335.

22. Guirakhoo F, Zhang ZX, Chambers TJ, Delagrave S, Arroyo J, Barrett AD, Monath TP: Immunogenicity, genetic stability, and protective efficacy of a recombinant, chimeric yellow fever-Japanese encephalitis virus (ChimeriVax-JE) as a live, attenuated vaccine candidate against Japanese encephalitis. Virology 1999, 257:363-372.

23. Appaiahgari MB, Vrati S: Clinical development of IMOJEV (R)-a recombinant Japanese encephalitis chimeric vaccine (JE-CV). Expert Opin Biol Ther 2012, 12:1251-1263.

24. Halstead SB, Thomas SJ: New Japanese encephalitis vaccines: alternatives to production in mouse brain. Expert Rev Vaccines 2011, 10:355-364.

25. Halstead SB, Thomas SJ: New vaccines for Japanese encephalitis. Curr Infect Dis Rep 2010, 12:174-180.26.

26. Heinz FX, Stiasny K: Flaviviruses and flavivirus vaccines. Vaccine 2012, 30:4301-4306.27.

27. Yasuda A, Kimura-Kuroda J, Ogimoto M, Miyamoto M, Sata T, Sato T, Takamura C, Kurata T, Kojima A, Yasui K: Induction of protective immunity in animals vaccinated with recombinant vaccinia viruses that express PreM and E glycoproteins of Japanese encephalitis virus. J Virol 1990, 64:2788-2795.

28. Konishi E, Pincus S, Paoletti E, Shope RE, Burrage T, Mason PW: Mice immunized with a subviral particle containing the Japanese encephalitis virus prM/M and $\mathrm{E}$ proteins are protected from lethal JEV infection. Virology 1992, 188:714-720.

29. Sato T, Takamura C, Yasuda A, Miyamoto M, Kamogawa K, Yasui K: High-level expression of the Japanese encephalitis virus $\mathrm{E}$ protein by recombinant vaccinia virus and enhancement of its extracellular release by the NS3 gene product. Virology 1993, 192:483-490.

30. Konishi E, Yamaoka M, Khin Sane W, Kurane I, Mason PW: Induction of protective immunity against Japanese encephalitis in mice by immunization with a plasmid encoding Japanese encephalitis virus premembrane and envelope genes. J Virol 1998, 72:4925-4930.

31. Kojima A, Yasuda A, Asanuma H, Ishikawa T, Takamizawa A, Yasui K, Kurata T: Stable high-producer cell clone expressing virus-like particles of the Japanese encephalitis virus e protein for a second-generation subunit vaccine. J Virol 2003, 77:8745-8755.32.

32. Hunt AR, Cropp CB, Chang GJ: A recombinant particulate antigen of Japanese encephalitis virus produced in stably-transformed cells is an effective noninfectious antigen and subunit immunogen. $J$ Virol Methods 2001, 97:133-149.

33. Konishi E, Fujii A, Mason PW: Generation and characterization of a mammalian cell line continuously expressing Japanese encephalitis virus subviral particles. J Virol 2001, 75:2204-2212.

34. Ikemura T: Codon usage and tRNA content in unicellular and multicellular organisms. Mol Biol Evol 1985, 2:13-34.

35. Andre S, Seed B, Eberle J, Schraut W, Bultmann A, Haas J: Increased immune response elicited by DNA vaccination with a synthetic gp120 sequence with optimized codon usage. J Virol 1998, 72:1497-1503.

36. zur Megede J, Chen MC, Doe B, Schaefer M, Greer CE, Selby M, Otten GR, Barnett SW: Increased expression and immunogenicity of sequence-modified human immunodeficiency virus type 1 gag gene. J Virol 2000, 74:2628-2635. 
37. Bolin SR, Ridpath JF, Black J, Macy M, Roblin R: Survey of cell lines in the American type culture collection for bovine viral diarrhea virus. J Virol Methods 1994, 48:211-221.

38. Kuhn RJ, Zhang W, Rossmann MG, Pletnev SV, Corver J, Lenches E, Jones CT, Mukhopadhyay S, Chipman PR, Strauss EG, Baker TS, Strauss JH: Structure of dengue virus: implications for flavivirus organization, maturation, and fusion. Cell 2002, 108:717-725.

39. Heinz FX, Allison SL: Structures and mechanisms in flavivirus fusion. Adv Virus Res 2000, 55:231-269.40.

40. Yamaji H, Segawa M, Nakamura M, Katsuda T, Kuwahara M, Konishi E: Production of Japanese encephalitis virus-like particles using the baculovirus-insect cell system. J Biosci Bioeng 2012, 114(6):657-662.

41. Yamaji H, Nakamura M, Kuwahara M, Takahashi Y, Katsuda T, Konishi E: Efficient production of Japanese encephalitis virus-like particles by recombinant lepidopteran insect cells. Appl Microbiol Biotechnol 2013, 97(3):1071-1079.

42. Dejnirattisai W, Jumnainsong A, Onsirisakul N, Fitton P, Vasanawathana $S$, Limpitikul W, Puttikhunt C, Edwards C, Duangchinda T, Supasa S, Chawansuntati K, Malasit P, Mongkolsapaya J, Screaton G: Cross-reacting antibodies enhance dengue virus infection in humans. Science 2010, 328(5979):745-748.

43. Beltramello M, Williams KL, Simmons CP, Macagno A, Simonelli L, Quyen NT, Sukupolvi-Petty S, Navarro-Sanchez E, Young PR, de Silva AM, Rey FA, Varani L, Whitehead SS, Diamond MS, Harris E, Lanzavecchia A, Sallusto F: The human immune response to dengue virus is dominated by highly cross-reactive antibodies endowed with neutralizing and enhancing activity. Cell Host Microbe 2010, 8(3):271-283.

44. Hua RH, Bu ZG: A monoclonal antibody against PrM/M protein of Japanese encephalitis virus. Hybridoma (LarChmt) 2011, 30:451-456

45. Hua RH, Liu LK, Chen ZS, Li YN, Bu ZG: Comprehensive mapping antigenic epitopes of NS1 protein of Japanese encephalitis virus with monoclonal antibodies. PLoS One 2013, 8(6):e67553.

46. Hua RH, Liu LK, Huo H, Li YN, Guo LP, Wang XL, Qin CF, Bu ZG: Comprehensive mapping of a novel NS1 epitope conserved in flaviviruses within the Japanese encephalitis virus serocomplex. Virus Res 2014, 185:103-109.

doi:10.1186/1472-6750-14-62

Cite this article as: Hua et al.: Generation and characterization of a new mammalian cell line continuously expressing virus-like particles of Japanese encephalitis virus for a subunit vaccine candidate. $B M C$ Biotechnology 2014 14:62

\section{Submit your next manuscript to BioMed Central and take full advantage of:}

- Convenient online submission

- Thorough peer review

- No space constraints or color figure charges

- Immediate publication on acceptance

- Inclusion in PubMed, CAS, Scopus and Google Scholar

- Research which is freely available for redistribution 